\title{
Effects on $f_{0} F_{2}$ of Daytime and Nighttime Sudden Commencement Storms
}

\author{
A.C. Das, Girija Rajaram and R.G. Rastogi \\ Physical Research Laboratory, Ahmedabad-380009, India
}

(Received May 1, 1973; Revised August 1, 1973)

\begin{abstract}
The effect on $f_{0} F_{2}$ of daytime sudden commencement and nighttime sudden commencement storms is shown for equatorial, low-, mid- and highlatitude locations. It is seen that it is the mid-latitudes which show the greatest dependence on time of sudden commencement, and larger increases of $F$-region ionisation are seen in the evening to midnight hours as compared to day following a storm. Such prominent differences are not seen at the other latitudes. The mid-latitude observations are interpreted in terms of neutral thermospheric winds, and magnetospheric electric fields set up during disturbed conditions.
\end{abstract}

\section{Introduction}

The relationship between magnetic storms and $F$-region ionospheric storms has been a field of much investigation since the earliest work of HARANG (1937) and of Appleton et al. (1937). MARTyn (1953) found that at all latitudes, an ionospheric storm begins simultaneously, or within an hour after the sudden commencement of the magnetic storm, and the initial effect on the $F$-region depends on the local time of sudden commencement. Thomas and Venables (1966) suggested that the changes in $f_{0} F_{2}$ during a geomagnetic storm are decided by the local time of the main phase. They found at the mid-latitudes, if the main phase occurred at night there was an immediate decrease of $N_{\max } F_{2}$, but if the main phase occurred in the daytime there was either an increase in $N_{\max } F_{2}$ or no change. Jones (1971) from studies of $N_{\max }$ and $N_{T}$ at a midlatitude station went further to say that the main phase of a magnetic storm must occur between $08-12 \mathrm{hr}$ L.T. for any increase of $F$-region ionisation to be observed. Kiyanovskiy and Mednikova (1963) found that at mid-latitudes, negative disturbances in $f_{0} F_{2}$ lag behind geomagnetic disturbances by about 6 hours while positive disturbances show no relationship. SHASHun'Kina (1968) observed dependence of ionospheric effect on time of sudden commencement at mid-latitudes for high sunspot.

A study of the storm-time changes in $N_{\max } F_{2}$ for the station Slough separately for storms starting during daylight and during darkness was made by Thomas and Robins (1958). In this work, the dependence of storm-time $f_{0} F_{2}$ changes on the time of sudden commencement is shown for high-latitude, mid- 
latitude and low-latitude stations, and possible explanations given for the midlatitude characteristics.

\section{Method of Study}

About 100 storms of the IGY-IGC period (1957-1959) with $A_{p}$ exceeding 50 on any of the 3 days following the storm were taken for the analysis. Stations are classified as equatorial $\left(0-10^{\circ} \mathrm{dip}\right)$, low-latitude $\left(10-35^{\circ} \mathrm{dip}\right)$, midlatitude $\left(35-70^{\circ} \mathrm{dip}\right)$, and high-latitude (above $\left.70^{\circ} \mathrm{dip}\right)$. At these selected stations, the ratio (storm $f_{0} F_{2}$ )/(median $f_{0} F_{2}$ ) was averaged for each hour from zero hour (i.e., time of sudden commencement) to seventy-two hours after sudden commencement, to give $\operatorname{Dst}\left(f_{0} F_{2}\right)$. This was done separately for (1) storms which had their sudden commencement in the daytime any time between $06 \mathrm{hr}$ and $18 \mathrm{hr}$ (2) storms which had their sudden commencement in the nighttime any time between $18 \mathrm{hr}$ and $06 \mathrm{hr}$. A further sub-division into storms with sudden commencement in the forenoon (06-12), postnoon (12-18), pre-midnight $(18-00)$ and post-midnight (00-06) hours was tried, but the number of storms in each category was small and the variations obtained were not statistically significant.

\section{Observations}

\subsection{Dst $\left(f_{0} F_{2}\right)$ at equatorial and low-latitude stations}

Figure 1 shows the storm-time variation $\operatorname{Dst}\left(f_{0} F_{2}\right)$ for the equatorial stations, Huancayo in the West and Trivandrum in the East, for daytime sudden commencement and nighttime sudden commencement storms. At both stations the daytime sudden commencement storms show a positive type of variationi.e., after a brief decrease in the hours following sudden commencement, stormtime $f_{0} F_{2}$ shows an increase during the remaining duration of the storms. The nighttime sudden commencement storms show a clear positive variation at Huancayo, but at Trivandrum there is a greater tendency for the ratio to drop below 1.00. Such differences could arise from the differing magnetic field configurations in the two zones. The important point to be noticed is that the overall variation pattern of $f_{0} F_{2}$ is positive for both daytime sudden commencement and nighttime sudden commencement storms.

The $\operatorname{Dst}\left(f_{0} F_{2}\right)$ variation at low-latitudes is shown in Fig. 2. Talara and Tucuman lie in the northern and southern hemispheres in the West zone. Baguio and Singapore lie in the northern and southern hemispheres in the East zone. For daytime sudden commencement storms both at Baguio and Singapore, $f_{0} F_{2}$ is clearly depressed between $0 \mathrm{hr}$ and $24 \mathrm{hr}$ storm-time, with an increase in the later hours. Talara and Tucuman do not show this too clearly. For nighttime sudden commencement storms, at all stations, after an initial decrease 

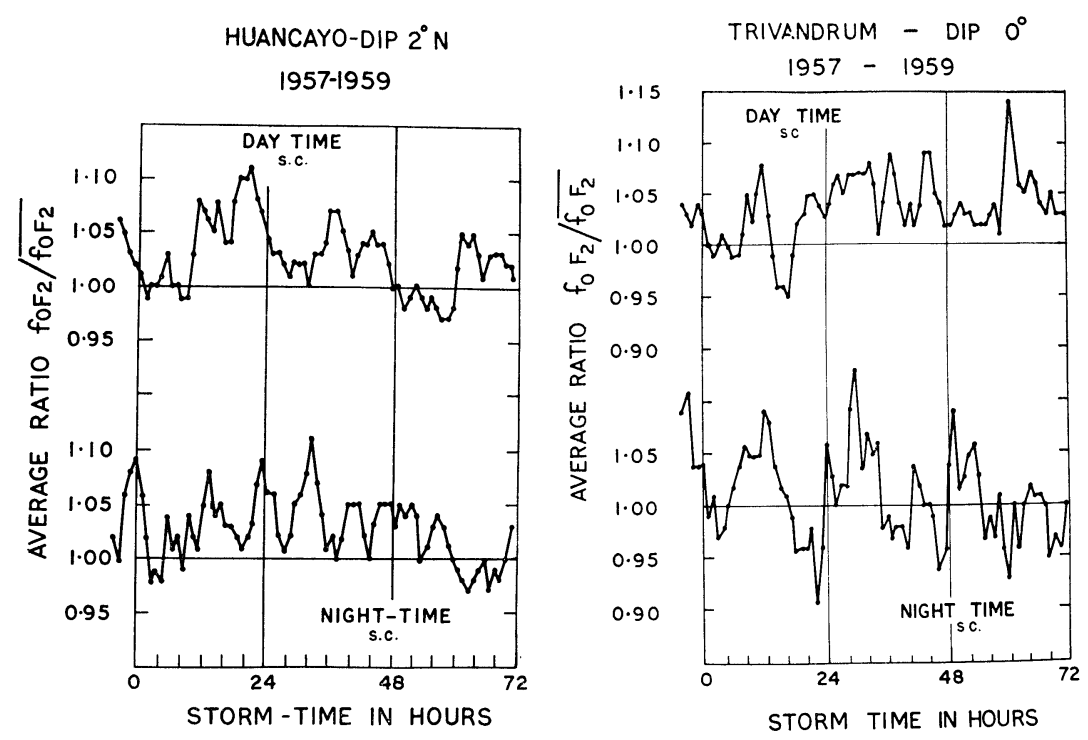

Fig. 1. Dst $\left(f_{0} F_{2}\right)$ for daytime sudden commencement and nighttime sudden commencement storms-equatorial latitudes.

following sudden commencement there is a positive trend in the ratio variation. The conclusion is that although there is some difference in the ratio variations exhibited by daytime and nighttime storms, they do not deviate much from a positive trend.

\subsection{Dst $\left(f_{0} F_{2}\right)$ at mid-latitude stations}

The behaviour of mid-latitude stations is seen in Fig. 3. Puerto Rico and Port Stanley lie in the northern and southern West zone, while Akita and Brisbane lie in the northern and southern East zone respectively. It is striking that the trend of $f_{0} F_{2}$ variations is exactly opposite for daytime sudden commencement and nighttime sudden commencement storms. In terms of stormtime, daytime sudden commencement storms show the following trend-a rise between $0 \mathrm{hr}$ and $12 \mathrm{hr}$, a fall between $12 \mathrm{hr}$ and $24 \mathrm{hr}$, a rise between $24 \mathrm{hr}$ and $36 \mathrm{hr}$, and then a gradual return to normal. The trend of the nighttime sudden commencement storms in terms of storm-time is, a fall between $0 \mathrm{hr}$ and $12 \mathrm{hr}$, a rise from $12 \mathrm{hr}$ to $24 \mathrm{hr}$, a drop from $24 \mathrm{hr}$ to $36 \mathrm{hr}$, and then a return to normal. Clearly the two trends are exactly opposite, and the correlation between the maxima of one and the minima of the other is marked, particularly during the first $36 \mathrm{hr}$ of the storm. This conclusion is supported by the $f_{0} F_{2}$ behaviour at three more mid-latitude stations as shown in Fig. 4-Wakkanai in the northern East zone, and Concepcion and Port Lockroy in the southern West zone. The trend of $f_{0} F_{2}$ variations for daytime sudden commencement and nighttime sudden commencement storms differs in precisely the same way as 

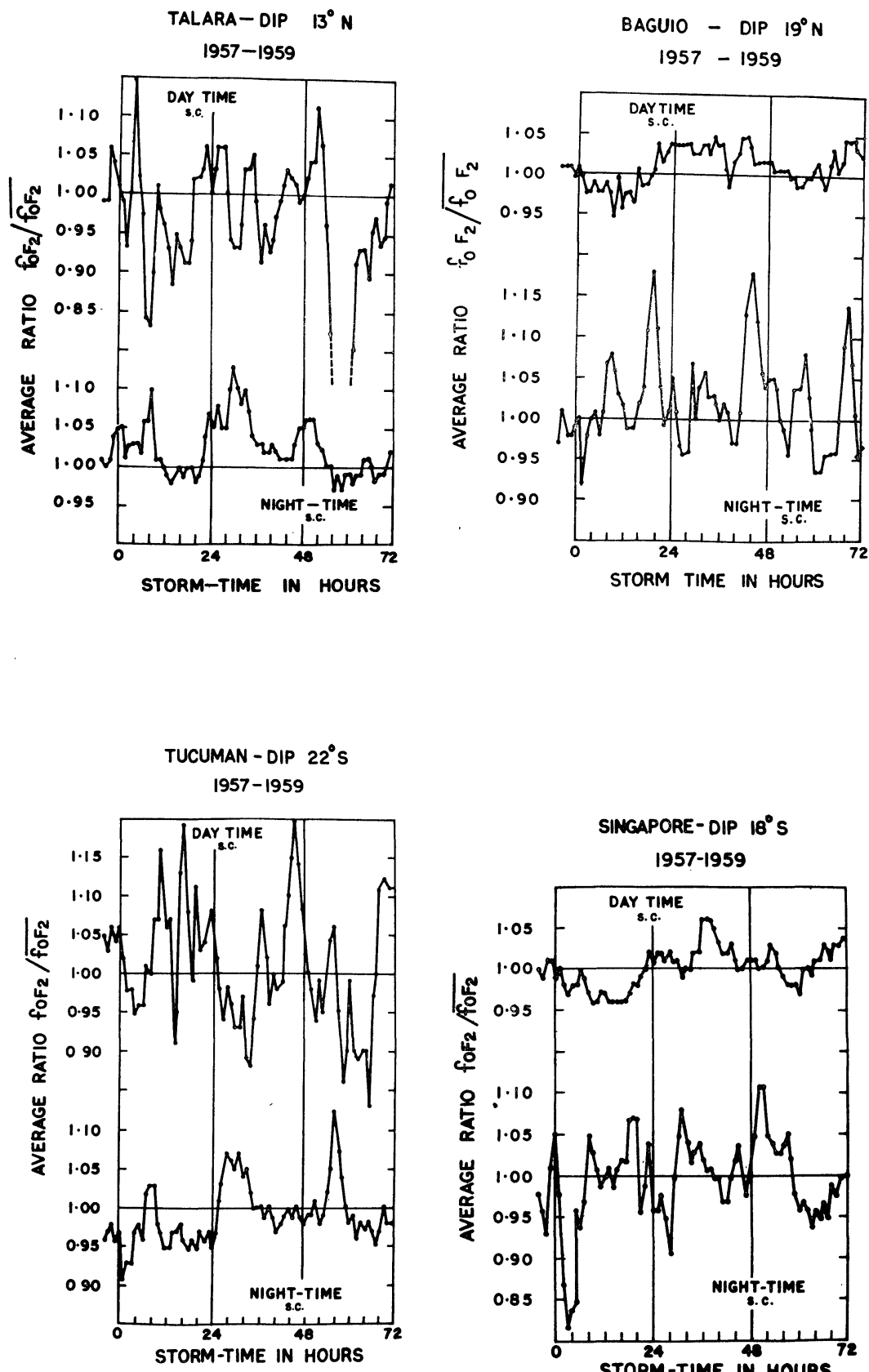

Fig. 2. $\operatorname{Dst}\left(f_{0} F_{2}\right)$ for daytime sudden commencement and nighttime sudden commencement storms-low-latitudes. 

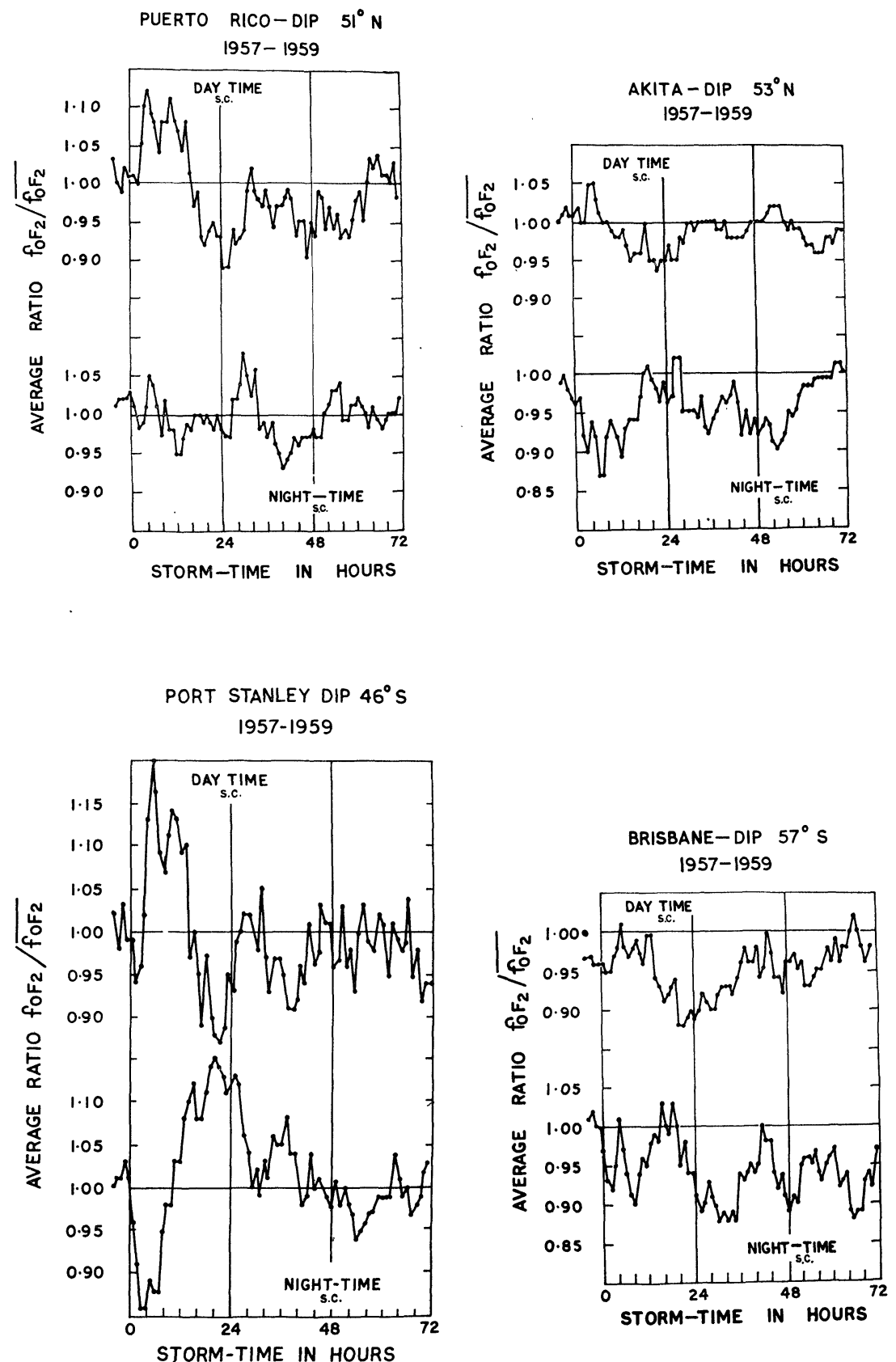

Fig. 3. Dst $\left(f_{0} F_{2}\right)$ for daytime sudden commencement and nighttime sudden commencement storms-mid-latitudes. 

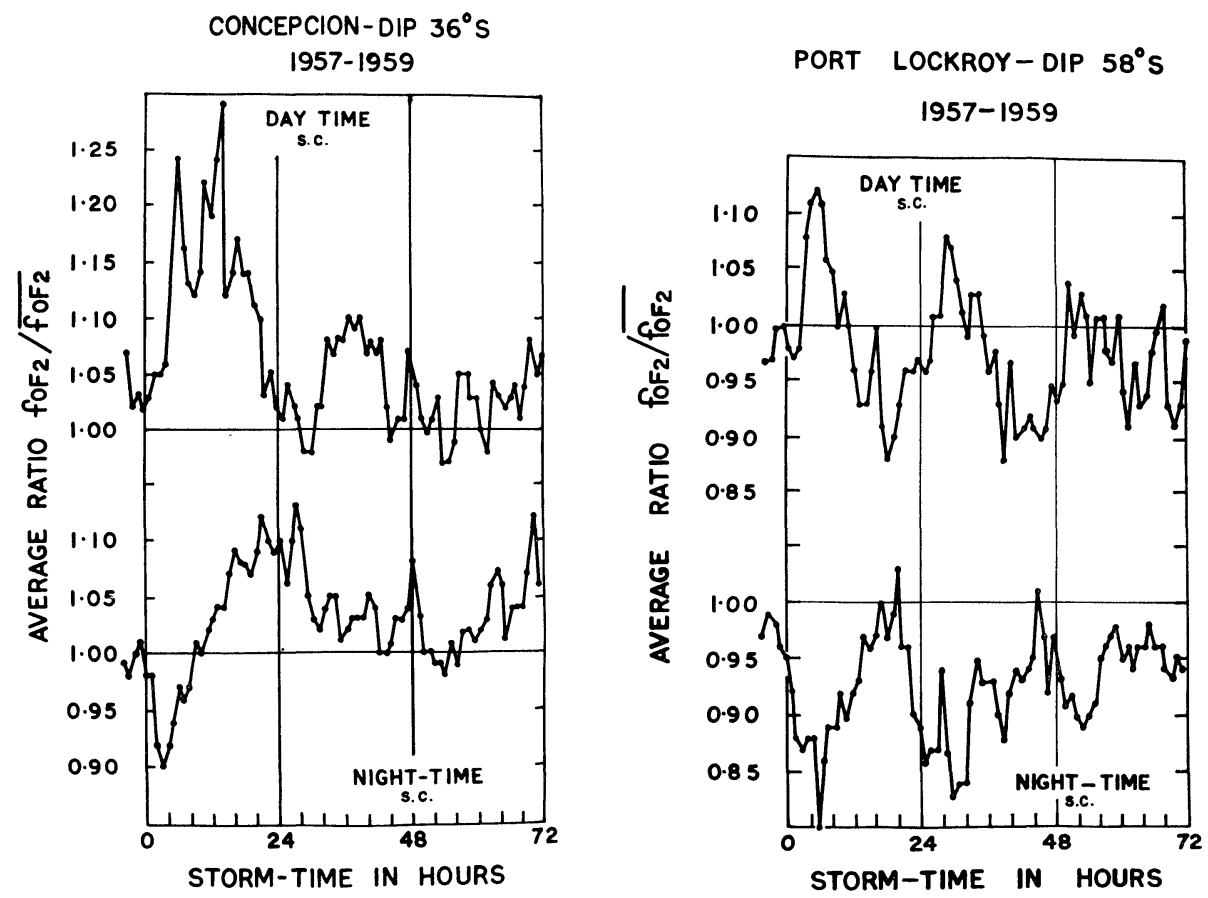

$$
\begin{gathered}
\text { WAKKANAI - DIP } 59^{\circ} \mathrm{N} \\
1957-1959
\end{gathered}
$$

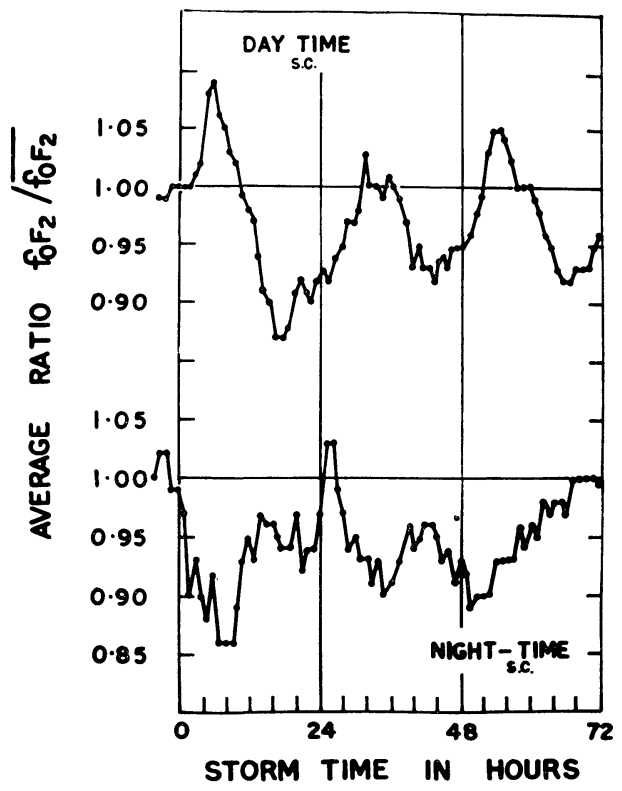

Fig. 4. $\operatorname{Dst}\left(f_{0} F_{2}\right)$ for daytime sudden commencement and nighttime sudden commencement storms at three more mid-latitude stations. 
described above, the correlation between the maxima of one and minima of the other being clearly seen in the first $36 \mathrm{hr}$ following sudden commencement.

On observing any one of these mid-latitude stations it is seen that the time of sudden commencement (i.e., $0 \mathrm{hr}$ storm-time) for the daytime sudden commencement storms is centred around $12 \mathrm{hr}$ noon, while that for the nighttime sudden commencement storms is centred around $00 \mathrm{hr}$ midnight. The vertical lines for $0 \mathrm{hr}, 24 \mathrm{hr}, 48 \mathrm{hr}$ and $72 \mathrm{hr}$ storm-time therefore, represent approximately hours around noon for the daytime sudden commencement storms, and around midnight for the nighttime sudden commencement storms. The indication then from these is that following a magnetic storm, $F$-region electron density increase is largest around evening to midnight hours, and less in the daytime hours. This gives a pronounced diurnal type of variation superimposed on the storm-time variation at these mid-latitude stations.

It may be argued that the method adopted in this study of classifying $\operatorname{Dst}\left(f_{0} F_{2}\right)$ separately into storms with sudden commencement in the daytime and nighttime will itself retain a good part of the SD or daily variation part of the disturbances. The fact remains however that this daily disturbance $\operatorname{SD}\left(f_{0} F_{2}\right)$ is most pronounced at these mid-latitudes, and is not so much at the high- and low-latitudes of the earth. This peculiarity has been pointed out by ОвAYASHI (1964).

\subsection{Dst $\left(f_{0} F_{2}\right)$ at high-latitude stations}

The high-latitude stations shown in Fig. 5 are Resolute Bay and South Pole in the West zone, and Tixie Bay and Scott Base in the East zone. At all the stations, frequent and large ratio fluctuations are seen for all $72 \mathrm{hr}$ following sudden commencement. This is true for both daytime sudden commencement and nighttime sudden commencement storms, and the general trend remains the same-peak negative values are at or before $24 \mathrm{hr}$, and then a gradual recovery to normal by $72 \mathrm{hr}$ follows. An interesting point is that the northern hemisphere stations show a depression of disturbed $f_{0} F_{2}$ before sudden commencement itself, for both daytime sudden commencement and nighttime sudden commencement storms. The cause of this is not understood, but it could have far-reaching implications in that the depression of $f_{0} F_{2}$ at these latitudes could perhaps predict the occurrence of ionospheric storms. It is certainly a feature which requires more study.

\subsection{Conclusions}

The above study brings out the following salient points:-

(1) The peak effect on $f_{0} F_{2}$ at all latitudes is around $24 \mathrm{hr}$ after storm sudden commencement in support of the results obtained by MARTYN (1953).

(2) Equatorial and low-latitude stations show an approximately positive trend for $f_{0} F_{2}$ variations following both daytime sudden commencement and 

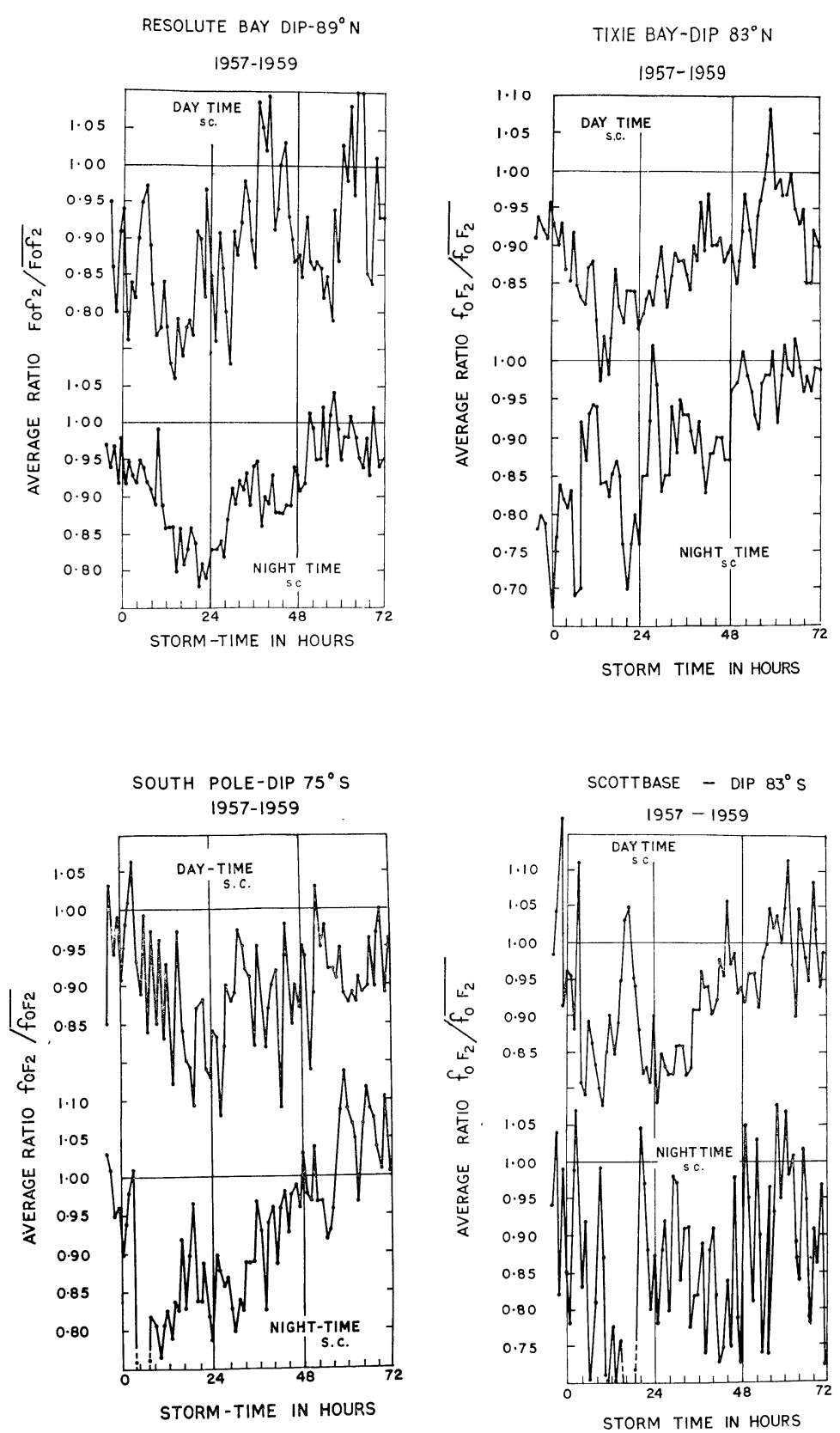

Fig. 5. Dst $\left(f_{0} F_{2}\right)$ for daytime sudden commencement and nighttime sudden commencement-high-latitudes. 
nighttime sudden commencement storms. High-latitudes show an approximately negative trend for $f_{0} F_{2}$ for both daytime and nighttime sudden commencement storms before recovery to normal.

(3) Mid-latitude stations show an opposite trend for daytime sudden commencement and nighttime sudden commencement storms, and the maxima of one correlates well with the minima of the other, particularly between $0 \mathrm{hr}$ and $36 \mathrm{hr}$ storm-time. The $F$-region electron density increase is more around evening to midnight hours than by day following a storm.

\section{Discussion}

\subsection{Effect of thermospheric winds and magnetospheric electric fields}

Analytical observations indicate that it is the mid-latitudes which are most unstable in their $F$-region response to magnetic storms. Disturbed $f_{0} F_{2}$ at lowand high-latitudes does not show this sharp dependence on season, time of sudden commencement, geomagnetic field asymmetry etc.

Storm-time $F$-region variations at mid-latitudes show a strong seasonal dependence with an increase in winter, and a decrease in summer (RASTOGI, 1962; Skinner and Wright, 1955; Matsushita, 1959). The asymmetry between northern and southern stations in storm-time $f_{0} F_{2}$ has been brought out by RAJARAm and Rastogi $(1968,1970)$ and is shown to be most marked at midlatitudes. In the present work we see the great dependence of storm $f_{0} F_{2}$ on the time of sudden commencement for mid-latitude stations.

KoHL and KING (1967) have emphasised the role of neutral thermospheric winds in bringing about $F$-region changes. The observations in this work too suggest that the mid-latitude $F$-region is greatly dependent on some agent (or agents) which changes from day to night, and from summer to winter. One such agent is the neutral wind at $F$-region heights. No direct observations of such quiet-time winds have been made but their existence does follow from the satellite drag measurements of JACCHIA and SLOWEy (1967). These winds would blow outwards from regions of high pressure to low pressure. They would thus blow from the summer to the winter hemisphere, and their overall direction be greatly dependent on the season. They would also change direction with the time of the day, blowing from the equator to the poles by day, and over the poles to the equator by night. In addition to these quiet-time winds one has to consider the equatorward winds which originate from the auroral regions at disturbed times, for which there is now growing experimental evidence (REEs, 1972; Cole, 1962; HoOK, 1970).

The net wind effect on the storm-time $F$-region would be the resultant of these two wind-systems. By day the quiet-time and storm-time winds blow in opposite directions and oppose each other. By night, both wind systems are directed towards the equator, and the effect is an additive one. It serves to lift 
ionisation upwards along the magnetic field lines, thereby decreasing losses due to recombination, and increasing the ionisation observed.

The authors believe it is this difference in the thermospheric wind pattern between day and night which is partly responsible for the opposite trend in $\operatorname{Dst}\left(f_{0} F_{2}\right)$ shown by mid-latitudes for daytime sudden commencement and nighttime sudden commencement storms. Овау ASH (1971) explains the equatorward movement of the border between positive and negative storm-effects in $N_{\max } F_{2}$ in terms of thermospheric winds generated across the plasmapause.

The vertical drift velocity component for a charged particle due to a horizontal neutral wind $U$ is given by

$$
W_{d}=U \sin I \cos I
$$

where $I$ is the magnetic dip of the station. This drift, $W_{d}$ would clearly be a maximum around $I=45^{\circ}$. As a consequence one would expect the mid-latitude electron density to be affected most by changes in $W_{d}$ arising from any changes in the thermospheric wind patterns. The role played by neutral winds in causing the winter-time enhancement of disturbed $f_{0} F_{2}$ at mid-latitudes has been discussed by RAJARAM et al. (1971). In that paper it was pointed out that the winter-time mid-latitude enhancement was more by night than by day, but the authors were unable to explain it then. The observations in the present paper clearly bring out that following storms, the $F$-region ionisation at mid-latitudes experiences much larger increase in the hours from evening to midnight than during day. It suggests that apart from thermospheric wind effects at midlatitudes, one also has to consider the electric fields which can be set up in the magnetosphere, and transferred to the ionosphere following disturbances.

The phenomenon of nighttime increase of ionisation at mid-latitudes following storms has been reported by PARK (1971) from a study of the $F$-region at Wallops Island. He explains these as caused by westward electric fields set up in the ionosphere during substorms. This westward field is supposed to enhance downward flux from the protonosphere while lowering the $F$-region. The reason why such westward electric fields should be set up at mid-latitudes is not clear.

One can however arrive at the concept of a radially-directed electric field in the equatorial plane of the magnetosphere in the following way. One starts with the general equations of motion for electrons and ions in the magnetosphere in the presence of an electric field. In the magnetosphere, the collisionfrequency of electrons with neutrals $\nu_{\text {en }}$, and the collision-frequency of ions with neutrals $\nu_{i n}$, are both small compared to the electron-ion collision-frequency $\nu_{\mathrm{e} i}$.

The solution of these equations of motion would be of the form

$$
\boldsymbol{V}_{\mathrm{e}_{\perp}}=\boldsymbol{U}_{0}-\boldsymbol{Q}_{\mathrm{e}}-\frac{c}{B^{2} \sigma}(\boldsymbol{j} \times \boldsymbol{B})+\frac{1}{\omega_{\mathrm{e}} B}\left(\boldsymbol{B} \times \frac{\mathrm{d} \boldsymbol{V}_{\mathrm{e}_{\perp}}}{\mathrm{d} t}\right) \quad\left(\omega_{\mathrm{e}}<0\right)
$$


and

where

$$
\boldsymbol{V}_{\mathrm{i}_{\perp}}=\boldsymbol{U}_{0}+\boldsymbol{Q}_{\mathrm{i}}-\frac{\boldsymbol{c}}{B^{2} \sigma}(\boldsymbol{j} \times \boldsymbol{B})+\frac{1}{\omega_{\mathrm{i}} \boldsymbol{B}}\left(\boldsymbol{B} \times \frac{\mathrm{d} \boldsymbol{V}_{\mathrm{i}_{\perp}}}{\mathrm{d} t}\right)
$$

and

$$
\begin{aligned}
\boldsymbol{U}_{0} & =c \frac{\boldsymbol{E} \times \boldsymbol{B}}{B^{2}} \\
\boldsymbol{Q}_{\mathrm{i}, \mathrm{e}} & =\frac{c}{B^{2} N|e|}\left(\boldsymbol{B} \times \nabla p_{\mathrm{i}, \mathrm{e}}\right)
\end{aligned}
$$

$$
\sigma=\frac{N e^{2}}{m_{\mathrm{e}} \nu_{\mathrm{ei}}}
$$

$V_{\mathrm{e}_{\perp}}$ and $V_{\mathrm{i}_{\perp}}$ are the mean mass velocities of electrons and ions across the magnetic field. Even in the quiet-time magnetosphere $V_{\mathrm{e}_{\perp}}$ and $V_{\mathrm{i}_{\perp}}$ will exist and will have differing values. $N$ is the number density for electrons and ions and $\nabla p_{i, e}$ is the pressure gradient term for electrons and ions. In Eqs. (1) and (2) the 3rd term on the R.H.S. can be neglected, as $\sigma$ for the magnetosphere is almost infinite. The fourth term on the R.H.S. is an inertial term and its contribution is small enough to be neglected. We also assume that in the undisturbed condition, there is no electric field, so $U_{0}=0$.

Equations (1) and (2), therefore are reduced to

$$
\begin{aligned}
& \boldsymbol{V}_{\mathrm{e}_{\perp}}=-Q_{\mathrm{e}} \\
& \boldsymbol{V}_{\mathrm{i}_{\perp}}=Q_{\mathrm{i}} .
\end{aligned}
$$

From Eqs. (3) and (4) it can be seen that in a region where the plasma pressure falls sufficiently rapidly with $L$, (where $L$ is the Mc Ilwain magnetic shell parameter) the azimuthal component of velocity $V_{i_{\perp}}$ for ions is towards the west, and that for electrons $V_{\mathrm{e}_{\perp}}$ is towards the east. Considered as a whole, since most of the mass is carried by the ions, magnetospheric plasma has a westward momentum of rotation with respect to the earth. Energy is injected into the magnetosphere in the form of hydromagnetic heating; this is a slow process which will heat the plasma, but is not likely to change the angular momentum. The hydromagnetic heating can change $Q_{\mathrm{e}}$ and $Q_{\mathrm{i}}$, but by itself does not change the moment of plasma rotation momentum (SHABANSKY, 1971). that

Therefore $r\left(m_{\mathrm{e}} \boldsymbol{V}_{\mathrm{e}_{\perp}}+m_{\mathrm{i}} \boldsymbol{V}_{\mathrm{i}_{\perp}}\right)=$ constant and since $m_{\mathrm{e}} / m_{\mathrm{i}} \rightarrow 0$ it can be shown

$$
\Delta V_{\mathrm{i}_{\perp}} \approx 0 \text {. }
$$

This hydromagnetic heating changes $Q_{\mathrm{e}}$ to $Q_{\mathrm{e}}^{\prime}$ and $Q_{\mathrm{i}}$ to $Q_{\mathrm{i}}^{\prime}$ such that $Q_{\mathrm{e}}^{\prime}=$ $Q_{\mathrm{e}}+\Delta Q_{\mathrm{e}}$ and $Q_{\mathrm{i}}^{\prime}=Q_{\mathrm{i}}+\Delta Q_{\mathrm{i}}$. In order to preserve the angular momentum we put

$$
\begin{aligned}
& V_{\mathrm{e}_{\perp}}^{\prime}=\alpha-Q_{\mathrm{e}}^{\prime} \\
& V_{\mathrm{i}_{\perp}}^{\prime}=\alpha+Q_{\mathrm{i}}^{\prime}
\end{aligned}
$$


and by using (5) it can be shown that $\alpha \approx-\Delta Q_{\mathrm{i}}$. Here $\alpha$ is controlled by ion heating and is equivalent to $U_{0}$ in Eqs. (1) and (2) and therefore is of the form $\boldsymbol{E} \times \boldsymbol{B} / B^{2} . \quad \alpha$ has the same value for electrons and ions, but is opposite in direction to $\Delta Q_{\mathrm{i}}$, and therefore is eastwards.

A velocity of the type $\alpha$ implies the presence of an electric field $\boldsymbol{E}$ directed radially inwards to earth in the equatorial plane. Such a field is set up within the magnetosphere during disturbed conditions, though it may diminish in intensity at distances nearer to earth. It will be transferred along the equipotential lines of force to the mid-latitude regions where it can come down to $F$-region or even $E$-region heights without much reduction. It sets up an $\boldsymbol{E} \times \boldsymbol{B}$ flow of plasma directed eastwards in the ionosphere from day to night, and night to day, concentric with the earth. This plasma flow has a tendency to wipe out the difference in ionization between day and night caused by differing solar U.V. flux - this difference is of an order of magnitude in the $F$-region. The plasma flow set up during disturbed conditions tends to relatively increase the nighttime ionisation and relatively decrease the daytime ionization in conformity with the results observed in the earlier part of this paper.

\subsection{Numerical estimate of plasma flow in the ionosphere}

From the expression for $Q$ given earlier, the ion mass velocity in the equatorial region is determined by

$$
Q_{\mathrm{i}} \approx \frac{c L^{3}}{|e| N B_{0} R_{\mathrm{e}}} \frac{\partial p}{\partial L}
$$

where

$$
p=\frac{2}{3} N \epsilon
$$

$\epsilon$ is the kinetic energy of protons in the magnetosphere measured in $\mathrm{keV}$. $B_{0}$-magnetic field at earth's surface

$R_{\mathrm{e}}$-radius of the earth.

If

$$
p=p_{0} L^{-\eta}
$$

where $\eta$ is an arbitrary constant.

Then

$$
Q_{\mathrm{i}} \approx \frac{c \eta L^{2}}{|e| B_{0} R_{\mathrm{e}}} \cdot \frac{2}{3} \epsilon
$$

Assuming $\eta=7$ for a rapid fall of plasma pressure $Q_{\mathrm{i}} \approx\left(0.3 \times 10^{3} L^{2} \epsilon\right) \mathrm{cm} / \mathrm{sec}$. For the mid-latitudes with $\phi \approx 60^{\circ}, L \approx 3, Q_{\mathrm{i}} \approx 2.7 \times 10^{3} \epsilon$.

The storm-time drift velocity in the magnetosphere can be calculated thus

$$
U_{0} \approx \Delta Q_{\mathrm{i}} \approx 2.7 \times 10^{3} \Delta \epsilon
$$


$\Delta \epsilon$ can be taken to be of the order of $\epsilon$, and is around $30 \mathrm{keV}$ for the magnetosphere (FRANK 1970).

Therefore $U_{0} \approx\left(8 \times 10^{2}\right) \mathrm{m} / \mathrm{sec}$.

The corresponding plasma drift velocity in the ionosphere $\bar{U}$ is

$$
\begin{aligned}
\bar{U} & =U_{0} \cos ^{3} \phi \\
& \approx 10^{2} \mathrm{~m} / \mathrm{sec} \quad \text { for } \phi=60^{\circ} .
\end{aligned}
$$

A eastward plasma flow velocity of $100 \mathrm{~m} / \mathrm{sec}$ should therefore be observed in the mid-latitudes following storms.

\subsection{Extent of electric field in the ionosphere}

The extent of the electric field in the ionosphere can be estimated thus.

The storm-time drift velocity in the magnetosphere

$$
U_{0}=\Delta Q=\frac{c}{B_{\mathrm{m}}|e|} \cdot \frac{2}{3} \frac{\Delta \epsilon}{\chi}
$$

where

$B_{\mathrm{m}}$ - magnetic field intensity in magnetosphere

$\chi$-characteristic length of plasma pressure inhomogeneity in magnetosphere.

Intensity of electric field in magnetosphere

$$
E_{\mathrm{m}} \approx U_{0} B_{\mathrm{m}} \approx \frac{c}{|e|} \cdot \frac{2}{3} \frac{\Delta \epsilon}{\chi} .
$$

Intensity of electric field in ionosphere $E_{\mathrm{i}}$ is

$$
E_{\mathrm{i}}=E_{\mathrm{m}} \cdot \frac{\chi}{l}
$$

where $l$ is the characteristic length in the ionosphere. Drift velocity in ionosphere

$$
\bar{U}=\frac{E_{\mathrm{i}}}{\dot{B}_{\mathrm{i}}}
$$

where $B_{\mathrm{i}}-$ magnetic field in the ionosphere

$$
\bar{U}=\frac{2}{3} \frac{c}{|e|} \frac{\Delta \epsilon}{B_{\mathrm{i}} l} .
$$

We have shown $\bar{U}=10^{2} \mathrm{~m} / \mathrm{sec}$ and taking $\Delta \epsilon=30 \mathrm{keV}, l \approx 6.7 \times 10^{3} \mathrm{~km}$.

This gives us the extent of the electric field in the ionosphere.

Clearly the storm effects in the mid-latitude $F$-region are due to both neutral thermospheric wind patterns, and magnetospheric electric fields with associated plasma flow patterns set up during disturbances. Both these features require more experimental observation. 
The authors express their gratitude to Professor K.R. Ramanathan for useful discussions, and to the memory of the late Professor Vikram Sarabhai for his great encouragement towards such studies of the Upper Atmosphere. They also thank the referees for suggesting the method of obtaining the extent of electric field.

\section{REFERENCES}

Appleton, E.V., R. Naismith and L.J. IngRam, British Radio Observations during the Second International Polar Year 1932-33, Phil. Trans. Roy Soc., A236, 191-259, 1937.

Cole, K.D., Joule heating of the Upper Atmosphere, Aust. J. of Phys., 15, 223-235, 1962.

FRANK, L.A., Further comments concerning low energy charged particle distributions within the earth's magnetosphere and its environs; in Particles and fields in the magnetosphere, edited by B.M.Mc Cormac, pp. 319-331, Reidel Publish Co., 1970.

HARANG, L., Storungen der Ionosphare und der Funkausbreitung Wahrend der Nordlichter und erdmagnetischen Storungen, Geophys. Publikasjoner, 11, 1-55, 1937.

Hook, J.L., Winds at the $75-110 \mathrm{~km}$ level at College, Alaska, Planet. Space Sci., 18, 1623-1638, 1970.

JACCHIA, L.G. and J. Slowey, The shape and location of the diurnal bulge in the Upper Atmosphere, Space Research, VII, 1077-1090, 1967.

Jones, K.L., Storm-time variation of $F_{2}$ layer electron concentration, J. Atmos. Terr. Phys., 33, 379-389, 1971.

KiYanovskiy, M.P. and N.V. Mednikova, The relationship between geomagnetic and ionospheric disturbances at middle latitudes, Geomagn. and Aeron., 3, 622-624, 1963.

KoHL, H. and J.W. KING, Atmospheric winds between 100 and $700 \mathrm{~km}$ and their effects on the ionosphere, J. Atmos. Terr. Phys., 29, 1045-1062, 1967.

MARTYN, D.F., Geo-morphology of $F_{2}$ region ionospheric storms, Nature, 171, 14-16, 1953.

Matsushita, S., A study of the morphology of ionospheric storms, J. Geophys. Res., 64, 305$321,1959$.

OBayashi, T., Morphology of storm in the ionosphere, from Research in Geophysics, edited by H. Odishaw, M.I.T. Press, 1, 335-336, 1964.

OBayashi, T., World-wide electron density changes and associated thermospheric winds during an ionospheric storm, Rep. of Space Science Deptt., University of Tokyo, Aug. 1, 1971.

PARK, C.G., Westward electric fields as the cause of nighttime enhancements in electron concentration in mid-latitude F-region, J. Geophys. Res., 76, 4560-4568, 1971.

Rajaram, G. and R.G. Rastogi, North-south asymmetry in storm-time variation of $f_{0} F_{2}, J$. Atmos. Terr. Phys., 30, 651-653, 1968.

Rajaram, G. and R.G. Rastogi, North-south asymmetry of ionospheric storms-dependence on longitude and season, J. Atmos. Terr. Phys., 32, 113-118, 1970.

Rajaram, G., A.C. Das and R.G. Rastogi, Ionospheric $F$-region disturbances and their possible mechanisms, Ann. de Geophys., 27, 469-475, 1971.

Rastogi, R.G., The effect of geomagnetic activity on the $F_{2}$ region over Central Africa, J. Geophys. Res., 67, 1367-1374, 1962.

REES, D., Winds and temperatures in the auroral zone and their relation to geomagnetic activity, Phil. Trans. Roy Soc., London, A271, 563-575, 1972.

Shabansky, V.P., Some processes in the magnetosphere, Space Sci. Rev., 12, 299-418, 1971.

SHASHUN'KINA, V.M., Ionospheric effect of the sudden commencement of a magnetic storm in years of maximum and minimum solar activity, Geomagn. and Aeronomy, 8, 149-151, 1968.

SkinNeR, N.J. and R.W.H. Wright, Some geomagnetic effects in the equatorial $F_{2}$-region, $J$. Atmos. Terr. Phys. 6, 177-188, 1955.

Thомas, J.O. and A. RobBins, The electron density distribution in the ionosphere over Slough(II) Disturbed Days, J. Atmos. Terr. Phys., 13, 131-139, 1958.

Thomas, L. and F.H. Venables, The onset of the $F$-region disturbance at middle latitudes during magnetic storms, J. Atmos. Terr. Phys., 28, 599-605, 1966. 